\title{
PENGARUH GAYA KEPEMIMPINAN, TINGKAT HIERARKI MORAL, DAN MOTIVASI TERHADAP KOMITMEN GURU
}

\author{
Pramudjono \\ Fakultas Keguruan dan Ilmu Pendidikan Universitas Mulawarman \\ email: pram_59@yahoo.co.id
}

\begin{abstract}
Abstrak: Penelitian bertujuan untuk mengetahui adanya hubungan antara gaya kepemimpinan, tingkat hierarki moral, dan motivasi terhadap komitmen guru. Sampel diambil dengan teknik proportional sampling dengan jumlah sebesar 450 orang guru dari populasi 796 guru SMA PNS di Samarinda. Data dikumpulkan dengan pemberian angket dan analisis data menggunakan teknik analisis jalur. Hasil penelitian menunjukkan bahwa (1) gaya kepemimpinan berpengaruh terhadap komitmen guru yang berarti peningkatan gaya kepemimpinan akan meningkatkan komitmen guru; (2) tingkat hierarki moral memiliki pengaruh pada komitmen guru yang berarti meningkatnya tingkat hierarki moral akan mengakibatkan peningkatan komitmen guru; (3) motivasi kerja guru memengaruhi komitmen guru yang berarti tingginya motivasi kerja akan menyebabkan tingginya komitmen; (4) gaya kepemimpinan berpengaruhterhadap motivasi kerja guru yang berarti peningkatan gaya kepemimpinan akan meningkatkan motivasi kerja guru; dan (5) tingkat hierarki moral memengaruhi motivasi kerja guru yang berarti meningkatnya tingkat hierarki moral akan meningkatkan motivasi kerja guru. Peningkatan aspek-aspek tersebut akan memperkuat komitmen para guru terhadap sekolah.
\end{abstract}

\section{Kata Kunci: komitmen, gaya kepemimpinan, tingkat hierarki moral, motivasi}

\section{THE INFLUENCE OF THE LEADERSHIP STYLES, MORAL HIERARCHY LEVELS, AND MOTIVATION TOWARDS TEACHER'S COMMITMENT}

\begin{abstract}
This study was aimed to find out the influence of the leadership styles, moral hierarchy levels, and motivation towards teachers' commitment. The sample taken using the proportional sampling technique consisting of 450 teachers out of 796 senior high school teachers in Samarinda. The data were collected using questionnaires and analyzed using the path analysis. The findings showed that (1) the leadership styles influence the teachers' commitment, meaning that an improvement in the leadership styles would improve the teachers' commitment; (2) the moral hierarchy levels influence the teachers' commitment, meaning that an improvement in the moral hierarchy levels would improve the teachers' commitment; (3) the motivation influence the teachers' commitment, meaning that the higher the motivation is, the higher the teachers' commitment is; (4) the leadership styles influence the teachers' motivation, meaning that an improvement in the leadership styles would improve the teachers' motivation; and (5) the moral hierarchy levels influence the teachers' motivation, meaning that an improvement in the moral hierarchy levels would improve the teachers' motivation. The improvement in those aspects would strengthen the teachers' commitment towards the schools.
\end{abstract}

Keywords: commitment, leadership styles, moral hierarchy levels, motivation

\section{PENDAHULUAN}

Usaha meningkatkan mutu pendidikan dapat dilakukan melalui komitmen karyawan sekolah. Usaha ini dapat berhasil jika partisipasi seluruh warga sekolah dapat melaksanakan aktivi- tasnya dan berkomitmen meningkatkan mutu sekolah. Komitmen guru merupakan bagian yang harus dilaksanakan oleh setiap warga sekolah karena hal tersebut penting untuk dilakukan oleh setiap warga sekolah. Tanpa melalui komitmen 
yang telah disepakati bersama mustahil tujuan pendidikan sekolah dapat tercapai.

Komitmen menjadi pendorong yang positif terhadap pelaksanaan tugas dan fungsi organisasi di lingkungan sekolah. Untuk itu, dibutuhkan guru yang memiliki kompetensi yang berupa pengetahuan, keterampilan, dan sikap perilaku yang diperlukan dalam pelaksanaan tugas. Hal tersebut dijelaskan dalam UU Guru dan Dosen No. 14 Tahun 2005 pasal 7 ayat 1b, profesi guru merupakan bidang pekerjaan khusus yang dilakukan berdasarkan prinsip memiliki komitmen untuk meningkatkan mutu pendidikan, keimanan, ketaqwaan, dan akhak mulia.

Hasil penelitian terhadap guru-guru SMA di Samarinda pada sekolah sebagai satuan pendidikan menunjukkan bahwa gaya kepemimpinan tidak berpengaruh terhadap motivasi kerja, sedangkan tingkat hierarki moral masih pada tingkat ke-2, yaitu tahap konvensional. Hal ini memberikan gambaran bahwa guru SMA menilai gaya kepemimpinan kepala sekolah terhadap motivasi masih rendah. Penyebab utamanya adalah guru kurang termotivasi, tidak adanya reward atas prestasi kerjanya, kepala sekolah membiarkan guru bekerja apa adanya tanpa komitmen yang telah diatur oleh sekolah. Hasil survei di tiga lokasi menunjukkan masih terdapat 20-30\% guru datang terlambat, absen tidak datang ke sekolah, janji kurang ditepati dalam melayani masyarakat, dan rendahnya pemenuhan standar isi dan standar proses. Lebih dari $30 \%$ guru belum memenuhi kompetensi yang disyaratakan dalam hal penguasaan materi yang di ujikan (Rachmad, 2009:67). Hal ini menunjukkan masih rendahnya komitmen guru dalam standar isi dan pengelolaan.

Studi komitmen guru tetap menarik untuk ditelaah dengan alasan (1) keberhasilan sekolah ditentukan oleh budaya sekolah;(2) sekolah merupakan organisasi yang kompleks dan unik membutuhkan guru yang memunyai tingkat hirarki moral tinggi (pasca konvensional); dan (3)

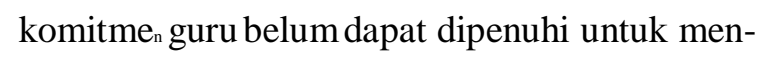
jaga dan menjamin sekolah bermutu baik dari input, proses, maupun output dan outcome.

Berdasarkan hasil survei dalam pra penelitian di sekolah tentang komitmen guru dalam meningkatkan mutu pendidikan, ditemukan bah- wa komitmen guru masih rendah dalam rangka mencapai tujuan sekolah. Hal ini dapat menjadi dasar atau alasan untuk meneliti komitmen guru. Di samping itu, juga untuk mengkaji teori pengaruh gaya kepemimpinan, tingkat hierarki moral, dan motivasi terhadap komitmen guru.

Faktor lain diduga memengaruhi komitmen guru adalah motivasi kerja. Motivasi kerja adalah dorongan yang timbul dari karyawan dalam mencapai tujuan sekolah. Sebagai usaha meningkatkan mutu pendidikan, komitmen dipengaruhi oleh motivasi kerja guru dalam meningkatkan mutu pendidikan dan rendahnya komitmen guru akan memengaruhi rendahnya mutu pendidikan. Pemberian reward pada karyawan merupakan salah satu dorongan yang timbul dariatasan untuk menumbuhkan komitmen kontinu di samping komitmen afektif dan komitmen normatif. Komitmen guru menjadi penting dalam meningkatkan mutu pendidikan sekolah melalui peningkatan budaya sekolah dan peningkatan tingkat hierarki moral.

Komitmen guru merupakan kekuatan batin yang datang dari dalam hati dan kekuatan dari luar guru itu sendiri tentang tugasnya yang dapat memberi pengaruh besar terhadap sikap guru berupa tanggung jawab dan responsif (inovatif) terhadap perkembangan ilmu pengetahuan dan teknologi. Griffin dan Moorhead (1986: 203) mengatakan bahwa komitmen organisasi adalah sikap yang mencerminkan sejauh mana seseorang individu mengenal dan terikat pada organisasinya. Seseorang individu yang memiliki komitmen tinggi kemungkinan akan melihat dirinya sebagai anggota sejati organisasi.

Luthans \& Doh (2009:135) mendefinisikan komitmen organisasi sebagai: (1) keinginan kuat untuk tetap sebagai anggota organisasi tertentu; (2) keinginan untuk berusaha keras sesuai keinginan organisasi; dan (3) keyakinan tertentu, dan penerimaan nilai dan tujuan organisasi.

Pengertian komitmen organisasi menurut Luthan (2009:274), "Organizational commitment is a worker's feelings and attitudes about the entire work organization." Di pihak lain, Syafaruddin (2001:87) mengatakan bahwa komitmen guru adalah sikap karyawan untuk tetap berada dalam organisasi dan terlibat dalam 
upaya-upaya mencapai misi, nilai-nilai dan tujuan organisasi. Komitmen merupakan suatu bentuk loyalitas yang lebih konkret yang dapat dilihat dari sejauh mana karyawan mencurahkan perhatiasn, gagasan, dan tanggung jawab dalam upaya mencapai tujuan organisasi.

Komitmen guru merupakan hal amat penting dalam upaya meningkatkan kinerja sekolah, baik secara personal maupun organisasional. Komitmen akan mendorong rasa percaya diri dan semangat kerja. Komitmen akan memperlancar pergerakan sekolah mencapai tujuan dalam konteks perubahan. Hal ini ditandai oleh terciptanya peningkatan, baik bersifat fisik maupun psikologis sehingga segala sesuatunya menjadi menyenangkan bagi seluruh warga sekolah. Komitmen adalah sikap yang merefleksikan loyalitas karyawan pada organisasi, dimana anggota organisasi mengekspresikan perhatiannya terhadap keberhasilan dan kemajuan organisasi secara berkelanjutan. Indikator-indikator komitmen adalah afektif, kontinuan, dan normatif.

Colquitt, et al. (2011:377-378) mendefinisikan kepemimpinan sebagai penggunaan kekuasaan dan pengaruh untuk mengarahkan aktivitas pengikut terhadap pencapaian tujuan. Seorang "pemimpin yang efektif" meningkatkan kinerja dan kesejahteraan unitnya secara keseluruhan, dinilai oleh margin keuntungan, produktivitas, biaya, absensi, retensi, survei karyawan, dan sebagainya. Seorang "pemimpin yang efektif" juga memupuk pemimpin berkualitas tinggi. Munculnya pemimpin dikaitkan dengan sejumlah sifat, termasuk hati nurani, keterbukaan, $e x-$ traversion, kemampuan kognitif umum, tingkat energi, toleransi stres, dan rasa percaya diri.

Pemimpin dapat menggunakan beberapa gaya untuk membuat keputusan. Kontrol pemimpin tinggi yang bergerak untuk mengontrol pengikut mereka termasuk otokratis, konsultatif, fasilitatif, dan delegatif gaya. Kepemimpinan transformasional memiliki hubungan positif moderat dengan kinerja dan hubungan positif yang kuat dengan kinerja dengan komitmen organisasi. Hal ini memiliki efek kuat pada hasilhasil dari perilaku kepemimpinan lainnya. Gaya pemimpin pengambilan keputusan mencerminkan proses penggunaan pemimpin untuk meng- hasilkan dan memilih dari satu set alternatif untuk memecahkan masalah.

Dalam gaya fasilitatif, pemimpin menyajikan masalah kepada sekelompok karyawan dan mencari konsensus tentang solusi, memastikan bahwa pendapat sendiri tidak menerima lebih berat daripada orang lain. Dengan gaya ini, pemimpin adalah fasilitator lebih dari pengambil keputusan. Dengan gaya delegatif, pemimpin memberikan karyawan individu atau kelompok karyawan tanggung jawab untuk membuat keputusan dalam beberapa kondisi batas yang ditentukan. Pemimpin tidak memainkan peranan dalam musyawarah, kecuali diminta meskipun ia mungkin menawarkan dorongan dan menyediakan sumber daya yang diperlukan di belakang layar.

Berdasarkan pendapat di atas, yang dimaksud dengan gaya kepemimpinan adalah pola perilaku pimpinan dalam memengaruhi dan menggerakkan karyawan untuk mencapai tujuan. Indikator-indikator directive, supportive, partisipative, dan achievement oriented.

Moral merupakan suatu standar salah atau benar bagi seseorang. Moral merupakan larangan yang membicarakan salah atau benar (Mulyono, 2009:96). Sementara itu, Tafsir, dkk. (2002:135) mengemukakan bahwa untuk memahami moral sebagai ajaran-ajaran wejanganwejangan, khotbah-khotbah, dan patokan-patokan tentang bagaimana manusia harus hidup dan bertindak agar menjadi manusia yang baik. Moral merupakan keyakinan tentang aturanaturan atau ajaran-ajaran yang baik dan buruk, benar dan salah, layak dan tidak layak, patut dan tidak patut yang bersumber dari agama, nasihat orang tua atau orang bijak maupun lingkungan sosial dan memengaruhi manusia dalam bertingkah laku sehari-hari.

Di pihak lain, Kohlberg (1995) lebih menekankan aspek kognisi dalam melihat perkembangan moral. Kohlberg lebih menitikberatkan struktur pemikiran daripada isi pemikiran seseorang. Ada dua keuntungan dengan menganggap penalaran moral sebagai struktur dan bukan isi. Pertama, apabila penalaran moral dianggap sebagai isi, apa yang baik dan buruk terkait dengan prinsip filosofis moralitas sehingga pena- 
laran moral bersifat universal. Universalitas moral berarti semua kultur memunyai konsep dasar moralitas yang sama, misalnya: cinta, hormat, kemerdekaan. Kedua, bila penalaran moral dianggap sebagai isi, orang tidak dapat membedakan penalaran moral anak-anak dengan dewasa. Sebaliknya, dengan menganggap penalaran moral sebagai struktur akan memungkinkan untuk mengidentifikasi perkembangan moral. Tingkat hierarki moral adalah ukuran tinggi rendahnya moral seseorang berdasarkan penalaran moralnya, indikator-indikator hierarki moral dari prakonvensional, konvensional, dan pascakonvensional.

Motivasi merupakan kekuatan atau motor pendorong kegiatan seseorang ke arah tujuan tertentu dan melibatkan berbagai kemampuan yang dimiliki untuk mencapainya. Pegawai di dalam proses produksi adalah sebagai manusia (individu) yang memiliki identifikasi antara lain: tabiat, sikap perilaku atsu penampilan, kebutuhan, keinginan, cita-cita, kebiasaan yang dibentuk keadaan, dan keadaan lingkungan dan pengalaman pegawai. Faktor di atas memengaruhi tinggi rendahnya komitmen (Sedarmayanti, 2009:214).

Luthans \& Doh (2009:394) menyatakan bahwa motivasi adalah sebuah proses psikologis melalui ketidakpuasan keinginan atau kebutuhan utama menggerakkan yang ditujukan untuk tujuan atau insentif. Motivasi dibagi menjadi dua motivasi intrinsik dan motivasi ekstrinsik. Motivasi intrinsik adalah sebuah penentu motivasi dimana penggenapan pengalaman individu melalui pelaksanaan kegiatan dan membantu orang lain. Motivasi ekstrinsik adalah sebuah penentu motivasi di mana lingkungan eksternal dan hasil dari kegiatan ini adalah lebih penting karena persaingan dan kompensasi atau perencanaan insentif.

Motivasi adalah kecenderungan emosional yang membimbing atau memfasilitasi pencapaian tujuan yang terdiri atas prestasi, inisiatif, dan optimisme. Motivasi penting karena komitmen adalah fungsi dari dua faktor, yakni motivasi dan kemampuan. Komitmen yang baik lahir dari keseimbangan motivasi dan kemampuan. Kemampuan tinggi untuk melakukan peker- jaan dengan baik membutuhkan ganjaran sebagai motivasi. Hal ini dipertegas Dessler (2011) yang menghubungkan motivasi dengan ganjaran (insentif). Menjadi motivator merupakan salah satu pekerjaan manajemen yang sederhana, tetapi juga paling rumit. Motivasi merupakan hal yang sederhana karena orang-orang pada dasarnya termotivasi atau terdorong untuk berprilaku dalam cara tertentu yang dirasakan mengarah kepada perolehan ganjaran (insentif).

Akhirnya, berdasarkan kajian teoretis dan fakta yang ada, bahwa komitmen diduga berperan dalam meningkatkan mutu pendidikan sekolah. Untuk itu, peneliti ingin menguji suatu model hubungan variabel langsung, antara komitmen dengan motivasi, tingkat hierarki moral, dan gaya kepemimpinan, yang dirumuskan dalam masalah penelitian seperti berikut. (1) Apakah terdapat pengaruh gaya kepemimpinan terhadap komitmen guru? (2) Apakah terdapat pengaruh tingkat hierarki moral terhadap komitmen guru? (3) Apakah terdapat pengaruh motivasi kerja guru terhadap komitmen guru? (4) Apakah terdapat pengaruh gaya kepemimpinan terhadap motivasi kerja? (5) Apakah terdapat pengaruh tingkat hierarki moral terhadap motivasi kerja?

\section{METODE}

Populasi penelitian adalah seluruh guru SMA di Kota Samarinda. Teknik pengambilan sampel digunakan penarikan sampel dilakukan secara proprosional sampling. Jumlah sampel adalah 450 guru dari jumlah populasi sebanyak 796 orang guru PNS. Teknik pengumpulan data dilakukan dengan menggunakan kuesioner. Angket diujicobakan untuk mengetahui validitas dan reliabelitas dan berdasarkan uji coba tersebut angket dapat digunakan untuk penelitian.

Teknik Analisis data menggunakan analisis jalur (path analysis) untuk mengetahui pengaruh antarvariabel sesuai dengan model kausal yang terbentuk. Adapun tahapan teknik analisis jalur yang didahului dengan uji persyaratan analisis dengan menggunakan uji normalitas dan uji linearitas regresi dengan Anava dan uji hipotesis dilakukan dengan menggunakan analisis uji signifikansi t. 
HASIL DAN PEMBAHASAN

Hasil

\section{Uji Persyaratan}

Untuk uji normalitas data digunakan rumus Lilliefors dan galat taksiran, dengan menggunakan taraf signifikan $\alpha=0,05$ bahwa seluruh nilai $\mathrm{L}_{0}$ diperoleh menunjukkan nilai lebih kecil dari nilai $\mathrm{L}_{\text {tabel. }}$. Dengan demikian, dapat dikatakan $\mathrm{H}_{0}$ diterima. Keputusannya adalah data sampel pada setiap variabel berasal dari populasi yang memiliki sebaran normal. Hasil uji linieritas juga menunjukkan bahwa semua prasyarat dipenuhi.

\section{Pengujian Hipotesis}

Perhitungan statistik dan uraian hubungan kausal dapat dijelaskan bahwa semua variabel eksogen berpengaruh secara nyata dengan variabel endogen terhadap motivasi kerja guru $\left(\mathrm{X}_{3}\right)$. Hasil pengujian hipotesis penelitian koefisien jalur dapat pada uji analisis jalur struktur 1 dan uji analisis jalur struktur 2. Hasil perhitungan koefisien jalur dapat disajikan pada Tabel 1 analisis jalur pada model substruktur-1.

Berdasarkan Tabel 1 model substruktur1 , setelah uji analisis menunjukkan hasil sebagaimana ditunjukkan pada Gambar 1.

Hasil perhitungan pada koefisien jalur pada model substruktur-2 disajikan pada Tabel 2 .

Tabel 1: Koefisien Jalur Model Struktur -1

\begin{tabular}{llllll}
\hline Jalur & & $\begin{array}{l}\text { Koefisien } \\
\text { Jalur }\end{array}$ & t hitung & $\begin{array}{l}\text { Signifikasi } \\
\alpha\end{array}$ & Hasil Uji \\
\hline $\mathrm{X}_{1} \mathrm{Y}$ & $\rho_{\mathrm{y} 1}$ & 0,423 & 7,625 & 0,000 & Sangat signifikan \\
$\mathrm{X}_{2} \mathrm{Y}$ & $\rho_{\mathrm{y} 2}$ & 0,378 & 6,344 & 0,000 & Sangat signifikan \\
$\mathrm{X}_{3} \mathrm{Y}$ & $\rho_{\mathrm{y} 3}$ & 0,411 & 7,630 & 0,000 & Sangat signifikan \\
\hline
\end{tabular}

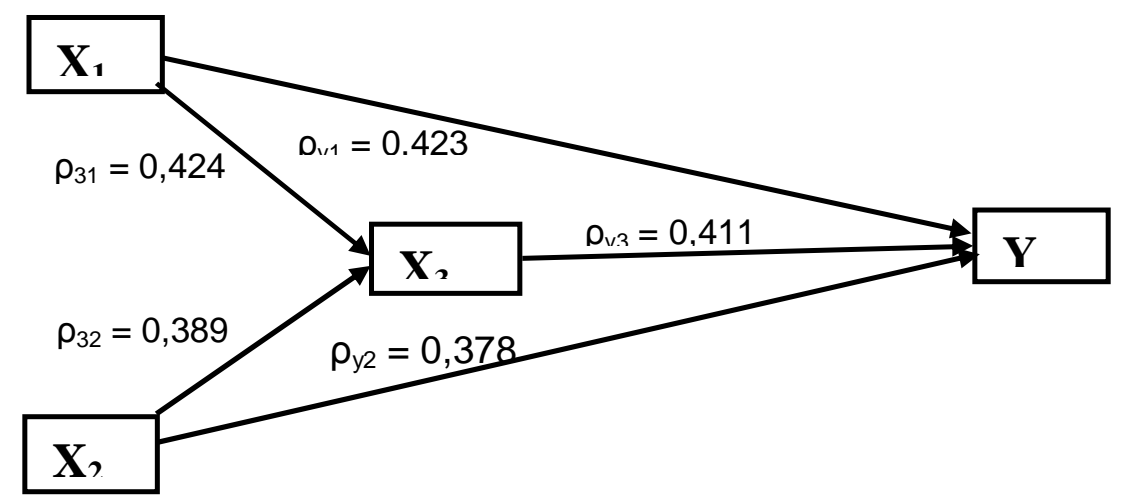

Gambar 1. Model Empirik Hubungan Antarvariabel pada Model Substruktur Berdasarkan Hasil Analisis Jalur

Tabel 2: Koefisien Jalur Model Struktur-2

\begin{tabular}{llllll}
\hline Jalur & & $\begin{array}{l}\text { Koefisien } \\
\text { Jalur }\end{array}$ & t hitung & $\begin{array}{l}\text { Signifikasi } \\
\alpha\end{array}$ & Hasil Uji \\
\hline $\mathrm{X}_{1} \mathrm{X}_{3}$ & $\rho_{31}$ & 0,424 & 6,354 & 0,000 & Sangat signifikan \\
$\mathrm{X}_{2} \mathrm{X}_{3}$ & $\rho_{32}$ & 0,389 & 5,473 & 0,000 & Sangat signifikan \\
\hline
\end{tabular}




\section{Pembahasan}

Berdasarkan uraian teori dan pembuktian empirik, terbukti bahwa gaya kepemimpinan berpengaruh terhadap komitmen guru. Dengan demikian, variasi tinggi rendahnya variabel komitmen guru dipengaruhi langsung oleh variabel gaya kepemimpinan, dan variabel komitmen guru dipengaruhi tidak langsung variabel gaya kepemimpinan melalui motivasi kerja guru. Rafiq (2010:67) menjelaskan bahwa gaya kepemimpinan berpengaruh pada komitmen dan bahwa komitmen yang tinggi dibangun melalui gaya kepemimpinan yang baik. Dengan kata lain, komitmen yang tinggi dapat dibenntuk melalui gaya kepemimpinan yang baik.

Tingkat hierarki moral berpengaruh terhadap komitmen guru. Dengan demikian, variasi tinggi rendahnya variabel komitmen guru dipengaruhi langsung oleh variabel tingkat hierarki moral, dan variabel komitmen guru dipengaruhi tidak langsung oleh variabel tingkat hirarki moral melalui motivasi kerja guru. Dengan kata lain, tingkat hierarki moral yang tinggi akan mengakibatkan komitmen guru tinggi dan tingkat hierarki moral tinggi akan mengakibatkan komitmen guru yang tinggi melalui motivasi yang tinggi pula.

Motivasi kerja guru berpengaruh terhadap komitmen guru. Dengan demikian, variasi tinggi rendahnya variabel komitmen guru dipengaruhi variabel motivasi kerja guru, atau dengan kata lain motivasi kerja guru yang baik akan mengakibatkan komitmen guru yang baik pula. Hal ini sesuai dengan penelitian Burton \& Holtom (2002:181) bahwa terdapat pengaruh motivasi kerja terhadap komitmen guru, motivasi yang diberikan kepada guru akan memengaruhi komitmen guru dalam melaksanakan tugasnya. Mulyana (2013) menjelaskan terdapat hubungan antara komitmen dengan motivasi. Hal itu berarti bahwa jika guru memiliki komitmen yang tinggi terhadap pekerjaan, itu dipengaruhi oleh motivasi yang tinggi.

Hal ini sesuai dengan penelitian Silalahi (2008:1) yang menyatakan bahwa manusia bekerja membutuhkan motivasi kerja untuk menghasilkan suatu karya yang dapat membangun perusahaan dan akan memiliki efek positif pada dirinya sendiri sehingga tujuan bersama tercapai. Adanya Pemimpin yang dapat memotivasi karyawan dalam suatu perusahaan dan memberikan suatu perubahan yang menguntungkan banyak pihak. Dalam memotivasi karyawan, dibutuhkan pemimpin transformasional yang dapat membawa perubahan yang baik, mengetahui kebutuhan bawahannya serta dapat menanamkan dan memperkuat aspek-aspek budaya organisasi yang dikembangkan oleh perusahaan sehingga akan menumbuhkan komitmen organisasi pada karyawan. Brahmasari (2014:1) memberikan dukungan terhadap penelitian ini bahwa melalui motivasi kerja karyawan komitmen karyawan dapat ditingkatkan,

Gaya kepemimpinan berpengaruh terhadap motivasi kerja guru. Dengan demikian, variasi tinggi rendahnya variabel motivasi kerja guru dipengaruhi oleh variabel gaya kepemimpinan. Dengan kata lain, gaya kepemimpinan yang baik mengakibatkan motivasi kerja guru yang baik pula. Hal ini sejalan dengan penelitian Koesmono (2007:16) bahwa kepemimpinan memengaruhi komitmen karyawan dan kepemimpinan berpengaruh pada motivasi kerja baik secara langsung maupun tidak langsung. Dengan kata lain, gaya kepemimpinan yang baik akan mengakibatkan komitmen guru yang baik pula dan gaya kepemimpinan yang baik akan mengakibatkan komitmen guru yang baik melalui motivasi yang baik pula.

Azzuhri dan Herawati (2014:621) menjelaskan bahwa tipe gaya kepemimpinan transformasional memberikan pengaruh pada komitmen organisasi. Hal ini sejalan dengan penelitian yang dilakukan bahwa gaya kepemimpinan guru memberikan sumbangan pada komitmen guru dalam melaksanakan tugas sehari-hari. Tinggi rendahnya komitmen guru dalam melaksanakan tugas ditentukan oleh tinggi rendahnya kepemimpinan kepala sekolah.

Hasil penelitian ini mendukung penelitian Peter \& Crawford (1999) menyatakan bahwa gaya kepemimpinan berpengaruh pada komitmen yang berati semakin baik gaya kepemimpinan kepala sekolah akan memberikan penga- 
ruh pada komitmen yang baik pula. Hasil penelitian ini sesuai dengan penelitian Sitomorang (2014:47) yang menyimpulkan bahwa kepemimpinan berpengaruh langsung terhadap komitmen guru. Dukungn tersebut terjadi antara lain karena kedua penelitian ini sama-sama meneliti guru. Kepala sekolah dalam penelitian Sitomorang adalah guru yang diberi tugas tambahan sebagai kepala sekolah. Kedua penelitian samasama menggunakan pendekatan kuantitatif dengan teknik analisis jalur.

Tingkat hierarki moral berpengaruh terhadap motivasi kerja guru. Dengan demikian, variasi tinggi rendahnya variabel motivasi kerja guru dipengaruhi oleh variabel tingkat hierarki moral. Dengan kata lain, tingkat hierarki moral yang tinggi akan mengakibatkan motivasi kerja guru yang tinggi pula. McNamee (1977:37) dalam penelitiannya pengembangan moral berpengaruh pada motivasi kerja yang berarti bahwa tinggi rendahnya tingkat moral akan memengaruhi motivasi kerja guru.

\section{PENUTUP}

Hasil penelitian di atas menunjukkan halhal seperti berikut. Pertama, gaya kepemimpinan berpengaruhterhadap komitmen guru. Hal ini berarti, jika gaya kepemimpinan meningkat akan mengakibatkan peningkatan komitmen guru. Kedua, tingkat hierarki moral berpengaruh terhadap komitmen guru. Ini berarti, jika tingkat hierarki moral meningkat akan mengakibatkan peningkatan komitmen guru. Ketiga, motivasi kerja guru berpengaruh terhadap komitmen guru. Hal ini berarti jika motivasi kerja guru meningkat akan mengakibatkan peningkatan komitmen guru. Keempat, gaya kepemimpinan berpengaruh terhadap motivasi kerja guru. Hal ini berarti jika gaya kepemimpinan yang ada dalam sekolah-sekolah meningkat akan mengakibatkan peningkatan motivasi kerja guru. Kelima, tingkat hierarki moral berpengaruh terhadap motivasi kerja guru. Hal ini berarti jika tingkat hierarki moral meningkat akan mengakibatkan peningkatan motivasi kerja guru.

Berdasarkan hasil temuan di atas, dapat ditarik kesimpulan bahwa komitmen guru dapat ditingkat dengan meningkatkan gaya kepemim- pinan, tingkat hierarki moral, dan meningkatkan motivasi kerja.

\section{UCAPAN TERIMA KASIH}

Peneliti mengucapkan terima kasih kepada Dewan Redaksi Jurnal Cakrawala Pendidikan yang telah memberi saran bagi perbaikan dan memuat artikel ini.

\section{DAFTAR PUSTAKA}

Alwi, Syafaruddin. 2001. Manajemen Sumber Daya Manusia. Semarang: Badan Penerbit UNDIP.

Azzuhri, M dan Herawati. 2014. "Pengaruh Tipe Kepemimpinan Transformasional dan Transaksional Kepala Ruangan terhadap Komitmen Organisasional Perawat di RSI Unisma Malang". Jurnal JAM, Vol 12 No. 4 Tahun 2014.

Brahmasari, I.A. 2008. "Pengaruh Budaya Organisasi dan Motivasi Kerja terhadap Komitmen Karyawan dan Kinerja Perusahaan". Jurnal llmu Ekonomi dan Manajemen, Volume 5 Nomor 1 Oktober.

Burton, L. \& Holtom, 2002. "The Influence of Motivation to Attend, Ability to Attend, and Organizational Commitment on Different Types of Absence Behaviors". Journal of Managerial Issues Vol. 14, No. 2 (Summer 2002).

Colquitt, J.A., Lepine J.A., \& Wesson, M. 2011. Organizational Behavior Improving Performance and Commitmen in the Workplace. New York: McGraw Hill International Edition.

Dessler G. 2011. Fundamentals of Human Resource Management (2nd Edition). New Jersey: Prentice Hall.

Griffin, R.W., \& Moorhead, G. 1986. Organizing Behavior. Boston: Houghton Miffrin Cooperation. 
Koesmono, T. 2007. "Pengaruh Kepemimpinan dan Tuntutan Tugas terhadap Komitmen Organisasi dengan Variabel Moderasi Motivasi Perawat RSU Swasta Surabaya. Jurnal Manajemen dan Kewirausahaan, Vol. 9 No. 1, 2007.

Kohlberg, L. 1995. Tahap-tahap Perkembangan Moral. (Terjemahan John de San-to dan Agus Cremers SVD). Yogyakarta: Kanisius.

Luthans, F., \& Doh, J.P. 2009, International Management (Culture, Strategy, and Behavior). New York: McGraw-Hill. International.

Luthans, F. 2009. Organizational Behavior. Ninth edition. New York: McGraw-Hill.

McNamee. 1977. "Moral Behavior, Moral Development and Motivation". Journal of Moral Education, 7, 1, 27-31, October 1977.

Mulyana, Boyke. 2013. "Hubungan Konsep Diri, Komitmen, dan Motivasi Berprestasi dengan Prestasi Renang Gaya Bebas". Jurnal Cakrawala Pendidikan. November 2013, Th. XXXII, No. 3, hlm. 488-498..

Muryono, Sigit. 2009. Empati, Penalaran Moral dan Pola Asuh. Yogyakarta: Gala Ilmu Semesta.

Peter, L. \& Crawford, J. 1999. "The Relationship between Commitment and Organizational Culture, Subculture, Leadership Style and Job Satisfaction in Organizational Change and Development, Leadership \& Organization Development". Journal 20/7. Sidney: MCB University Press.
Rafiq, Awam Muhammad. 2010. Leadership Style, Organizational Culture and Job Commitment. Saarbrucken. Deutschland: VDM Verlag Dr. Muller.

Rachmad, Edi. 2009. Peta Kompetensi Guru dalam Pembelajaran Materi Ujian Nasional (UN) di Kalimantan Timur (Studi Uji Kompetensi Guru SD/MI, SMP/M.Ts, SMA/MA dan SMK/MK Tahun 2009. Samarinda: Lembaga Pendidikan dan Pelatihan Dewantara.

Sedarmayanti. 2009. Sumber Daya Manusia dan Produktivitas Kerja. Bandung: CV Mandar Maju.

Silalahi, B.Y. 2008. "Kepemimpinan Transformasional, Motivasi Kerja, Budaya Organisasi, dan Komitmen Organisasi”. Jurnal Elektronik Gunadarma, Vol. 2 No.1 Tahun 2008.

Sitomorang, B. 2014. "Faktor-faktor Penentu Komitmen Organisasi Kepala SMK". Cakrawala Pendidikan, Februari 2014, Th. XXXIII, No. 1, hlm. 39-49.

Tafsir, Arifin Z., Komarudin. 2002. Moralitas Al-Qur'an dan Tantangan Modernitas, Yogyakarta: Gama Mrdia.

Undang-Undang No.14 Tahun 2005 Tentang Guru dan Dosen. Jakarta: Asa Mandiri. 